\title{
Localization of Acetylcholine Receptors and Cholinesterase on Nerve-Contacted and Noncontacted Muscle Cells Grown in the Presence of Agents That Block Action Potentials
}

\author{
D. F. Davey and M. W. Cohen \\ Department of Physiology, McGill University, Montreal, Quebec H3G 1Y6, Canada
}

The possible role of nerve activity in triggering changes in the localization of acetylcholine receptors (AChRs) and cholinesterase (ChE) on nerve-contacted Xenopus muscle cells has been assessed. The localization of these molecules was examined on nerve-contacted and noncontacted muscle cells in cultures of spinal cord and myotomal muscle derived from Xenopus embryos. Sites of high $\mathrm{AChR}$ density were revealed by staining with fluorescent $\alpha$-bungarotoxin and sites of $\mathrm{ChE}$ localization were revealed histochemically. Localization of $\mathrm{AChRs}$ and $\mathrm{ChE}$ at sites of nerve-muscle contact occurred when the culture medium contained (a) $1.2 \mu \mathrm{M}$ tetrodotoxin (TTX), (b) $1.2 \mu \mathrm{M}$ TTX, $10 \mathrm{mM}$ magnesium, and no calcium salts, (c) $1.2 \mu \mathrm{M}$ TTX and $2 \mathrm{~mm}$ manganese, or (d) $106 \mathrm{~mm}$ potassium methyl sulfate instead of sodium chloride. The nerve-contacted muscle cells in each of these modified culture media also exhibited a reduced incidence of $\mathrm{AChR}$ and $\mathrm{ChE}$ patches away from the site of contact. It is concluded that the neural factor(s) that triggers the local and remote changes in $A C h R$ and $C h E$ distribution can be supplied to the neurites and externalized in the absence of nerve impulses, and that the nerve and muscle cells can interact even when they are largely depolarized.

The formation of the neuromuscular junction is associated with striking changes in the localization of AChRs and ChE, not only at the site of nerve-muscle contact, but also remote from that site. Locally, the nerve induces the development of a high density of AChRs and ChE, whereas elsewhere on the muscle cell the survival of any pre-existing sites of $\mathrm{AChR}$ and $\mathrm{ChE}$ localization is reduced and the formation of new postsynaptic-like sites is inhibited (Anderson and Cohen, 1977; Anderson et al., 1977; Braithwaite and Harris, 1979; Frank and Fischbach, 1979; Harris, 1981; Jacob and Lentz, 1979; Kuromi and Kidokoro, 1984; Lomo and Slater, 1980a, b; Moody-Corbett and Cohen, 1982; Rubin et al., 1980). Since these nerve-induced changes occur after the onset of synaptic transmission (Anderson et al., 1979; Bevan and Steinbach, 1977; Chow and Cohen, 1983; Harris, 1981; Kidokoro et al., 1980), the possibility arises that transmission-like processes may play a role in regulating their development. Studies employing neuromuscular blocking agents have indicated that nerve-induced changes in AChR localization can occur in the absence of muscle action potentials and activation of AChRs by the transmitter (Anderson and Cohen, 1977;

\footnotetext{
Received Jan. 11, 1985; revised July 17, 1985; accepted July 18, 1985.

We thank Mr. Claude Cantin for technical assistance. This work was supported by a grant from the Medical Research Council of Canada, and was conducted while one of us (D.F.D.) was on a Special Studies Programme of the University of Sydney.

Correspondence should be addressed to Dr. D. F. Davey, Department of Physiology F-13, University of Sydney, N.S.W. 2006, Australia, his permanent address. Copyright (c) 1986 Society for Neuroscience $0270-6474 / 86 / 030673-08 \$ 02.00 / 0$
}

Anderson et al., 1977; Rubin et al., 1980; Steinbach, 1974). This is also the case for the nerve-induced changes in $\mathrm{ChE}$ localization that occur in Xenopus myotomal muscle (Cohen et al., 1984; Moody-Corbett and Cohen, 1982; Moody-Corbett et al., 1982). By contrast, muscle impulse activity is important for the localization of ChE in rat (Cangiano et al., 1980; Lømo and Slater, 1980b; Weinberg and Hall, 1979) and avian muscles (Betz et al., 1980; Gordon et al., 1974; Rubin et al., 1980; but see Sohal and Wrenn, 1984).

In order to be able to interact with muscle, the neural factor (or factors) that triggers the changes in AChR and ChE localization must be present either on the external surface of the axons that contact the muscle cells or must be released from them. In either case, the production and/or externalization of the triggering factor might be dependent upon nerve impulse activity. Accordingly, in the present study we have examined the effects of impulse-blocking agents on the localization of $\mathrm{AChRs}$ and $\mathrm{ChE}$ in cultures of spinal cord and myotomal muscle obtained from Xenopus embryos. Since the development of many neurons, including Xenopus neurons, involves a transition from calcium-dependent to sodium-dependent action potentials (Spitzer, 1979, 1983), we examined the effects of agents that block the generation of both types of impulses. The results indicate that nerve-induced changes in AChR and ChE localization can occur in the absence of nerve impulses and also when the resting potential of the nerve and muscle cells is greatly reduced. Preliminary reports of this work have been published (Cohen et al., 1983; Davey and Cohen, 1982a, b; Moody-Corbett et al., 1983).

\section{Materials and Methods}

The techniques used to prepare the mixed nerve and muscle cultures were similar to those previously described (Anderson et al., 1977; MoodyCorbett and Cohen, 1981; Moody-Corbett and Cohen, 1982); the latter report should be consulted for greater detail. Two modifications to these methods were introduced. First, to allow cultured cells to be exposed to divalent cations such as manganese, which caused precipitation when added to standard L-15 culture medium, a special medium containing no salts but otherwise equivalent to L-15 was obtained (Gibco). Two parts of this medium were mixed with one part of a sterile stock solution of salts and buffer, producing a medium equivalent to the $67 \%$ L-15 used in previous studies except for the replacement of the phosphate buffer by $10 \mathrm{~mm}$ HEPES (pH 7.4). This medium was the basis of the control plating and maintenance media described below. Where required, the stock solution was modified to give test media with the stated final concentration of ions.

The second modification of the culture method was devised when it was found that freshly dissociated muscle cells lysed upon exposure to some divalent cations, such as manganese. To circumvent this problem, muscle cells were cultured in control medium for 2-4 $d$ before introducing the experimental medium. Nerve, obtained from the same embryos as the muscle cells, was dissociated and stored at $4^{\circ} \mathrm{C}$ in a HEPES-buffered medium supplemented with $0.2 \mu \mathrm{g} / \mathrm{ml}$ of Holmes' $\alpha-1$ - 
Table 1. The effect of impulse blocking agents on the localization of AChRs and ChE

\begin{tabular}{|c|c|c|c|c|c|}
\hline \multirow[b]{2}{*}{ Culture medium } & \multirow{2}{*}{$\begin{array}{l}\text { Stain at } \\
\text { contact } \\
\text { (\% nerve- } \\
\text { contacted } \\
\text { cells) } \\
\end{array}$} & \multicolumn{2}{|c|}{$\begin{array}{l}\text { Nonsynaptic stain on } \\
\text { lower surface (\% cells) }\end{array}$} & \multicolumn{2}{|c|}{$\begin{array}{l}\text { Nonsynaptic stain on } \\
\text { upper surface ( } \% \text { cells) }\end{array}$} \\
\hline & & $\begin{array}{l}\text { Nerve- } \\
\text { contacted } \\
\text { cells }\end{array}$ & $\begin{array}{l}\text { Cells not } \\
\text { contacted } \\
\text { by nerve }\end{array}$ & $\begin{array}{l}\text { Nerve- } \\
\text { contacted } \\
\text { cells }\end{array}$ & $\begin{array}{l}\text { Cells not } \\
\text { contacted } \\
\text { by nerve }\end{array}$ \\
\hline \multicolumn{6}{|l|}{ AChR stain } \\
\hline Previous studies ${ }^{a, b}$ & $63 \pm 9^{a}$ & $16 \pm 6^{b}$ & $96 \pm 2^{b}$ & $32 \pm 3^{b}$ & $84 \pm 3^{b}$ \\
\hline Control & $84 \pm 3$ & $2 \pm 2$ & $76 \pm 11$ & $10 \pm 5$ & $70 \pm 12$ \\
\hline TTX & $89 \pm 3$ & $1 \pm 1$ & $68 \pm 4$ & $12 \pm 2$ & $69 \pm 8$ \\
\hline Low $\mathrm{Ca}$, high $\mathrm{Mg}$, TTX & $82 \pm 4$ & $14 \pm 6$ & $75 \pm 6$ & $14 \pm 7$ & $72 \pm 12$ \\
\hline Mn, TTX & $77 \pm 3$ & $15 \pm 7$ & $81 \pm 3$ & $26 \pm 5$ & $66 \pm 6$ \\
\hline \multicolumn{6}{|l|}{ ChE stain } \\
\hline Previous studies $^{a, b}$ & $72 \pm 11^{a}$ & $83 \pm 5^{b}$ & $100 \pm 0^{b}$ & $57 \pm 4^{b}$ & $63 \pm 13^{b}$ \\
\hline Control & $79 \pm 1$ & $65 \pm 15$ & $100 \pm 0$ & $32 \pm 6$ & $63 \pm 13$ \\
\hline TTX & $85 \pm 2$ & $66 \pm 4$ & $98 \pm 2$ & $45 \pm 13$ & $77 \pm 3$ \\
\hline Low $\mathrm{Ca}$, high $\mathrm{Mg}$, TTX & $80 \pm 8$ & $45 \pm 3$ & $97 \pm 2$ & $8 \pm 6$ & $68 \pm 10$ \\
\hline Mn, TTX & $80 \pm 5$ & $55 \pm 4$ & $98 \pm 1$ & $21 \pm 9$ & $56 \pm 9$ \\
\hline
\end{tabular}

Nerve was plated $2-4 \mathrm{~d}$ after muscle and cultures were grown for a further $2-4 \mathrm{~d}$. Values (mean $\pm \mathrm{SE}$ ) are based on examination of 20-30 nerve-contacted muscle cells and 30 noncontacted muscle cells in each of 3-4 cultures grown in the same culture medium. Concentrations were as follows: TTX, $1.2 \mu \mathrm{mol} / \mathrm{liter}$; low Ca, $0 \mathrm{mmol} / \mathrm{liter}$; high $\mathrm{Mg}, 10$ $\mathrm{mmol} /$ liter; $\mathrm{Mn}, 2 \mathrm{mmol} /$ liter.

" From Moody-Corbett et al. (1982)

${ }^{b}$ From Moody-Corbett and Cohen (1982).

protein, i.e, a solution equivalent to the maintenance medium of previous studies mentioned above. This storage continued until the addition of the nerve to the muscle cultures. This modification, whereby nerve from the same embryos as the muscle cells was added to established muscle cultures in the presence of the desired culture medium, was adopted as the standard method in the present study.

The methods incorporating these modifications can be summarized as follows. With the aid of collagenase, myotomes and spinal cords of Xenopus laevis embryos (stages 21-24; Nieuwkoop and Faber, 1967) were isolated. The myotomes were dissociated into single cells by treatment with a calcium-magnesium-free solution of trypsin and EDTA. The muscle cells were plated on collagen-coated coverslips in a HEPESbuffered medium supplemented with $5 \%$ ( $\mathrm{vol} / \mathrm{vol}$ ) dialyzed horse serum. The culture chambers were sealed and maintained in the dark at room temperature. The spinal cords were cut into small lengths and dissociated in a calcium-magnesium-free solution for approximately $1 \mathrm{hr}$. The dissociated fragments were positioned over a plain glass coverslip in a Petri dish containing control HEPES-buffered maintenance medium. These fragments werc storcd at $4^{\circ} \mathrm{C}$ until addition to the muscle cultures. Only some fragments attached to the glass under these conditions; those that did adhered poorly.

After $1 \mathrm{~d}$ of muscle culture, the plating medium was replaced by a HEPES-buffered maintenance medium. After a further 1-3 d, the medium was renewed or replaced with a different one and the spinal cord fragments were added. Throughout the culture period, the condition and growth of both nerve and muscle were regularly assessed, using an inverted phase-contrast microscope.

To examine the development of nerve-muscle contacts under conditions of minimized membrane potential, an elevated potassium medium (denoted high $\mathrm{K}^{+}$) was prepared by replacing the normal $\mathrm{NaCl}$ by an equimolar concentration of potassium methyl sulfate. The final potassium ion concentration in the medium was $106 \mathrm{mmol} / \mathrm{liter}$. Two protocols were adopted. In Method 1, the muscle cells were plated in control medium and allowed to grow for 2-3 d. The medium was then progresively changed to the high $\mathrm{K}^{+}$medium over a period of about 1 $\mathrm{hr}$. This slow elevation of potassium ion concentration caused contractures in only a very small number of cells. The spinal cord explants were then added to the cultures. In Method 2, dissociated muscle cells and spinal cord explants were plated together into the high $\mathrm{K}^{+}$medium.

When cultures were found worthy of examination they were usually stained for both AChRs and ChE, although in a few cases, they were stained for only one of these molecules. The AChRs were stained with $\approx 0.1 \mu \mathrm{g} / \mathrm{ml}$ tetramethyl rhodamine $\alpha$-bungarotoxin (Anderson et al.,
1977; Cohen and Weldon, 1980) added to the culture medium. To assess ChE localization, the cultures were fixed $(45 \mathrm{~min}, 0.15 \%$ glutaraldehyde, $2 \%$ formaldehyde), then stained for ChE (Karnovsky, 1964; MoodyCorbett and Cohen, 1981). AChR and ChE staining were viewed with fluorescence and phase-contrast optics using $\times 6.3$ oculars and $a \times 63$ / 1.4 objective. In most cases, the localization of AChRs was assessed in living cultures in order to avoid masking of the stained AChRs by the ChE histochemistry (see Moody-Corbett and Cohen, 1981).

Quantitative assessment of $\mathrm{AChR}$ and $\mathrm{ChE}$ localization was made by answering the following questions (see Moody-Corbett and Cohen, 1982): Do the nerve-contacted muscle cells have stain localized at the site of nerve-muscle contact, away from the contact on the surface apposed to the floor of the culture dish (lower surface), and/or away from the contact on the upper surface; and do the noncontacted muscle cells have stain localized on their lower surface and/or upper surface? All patches of stain not at sites of nerve-muscle contact were considered nonsynaptic.

\section{Results}

\section{Control cultures}

The modified culture conditions used in the present study (substitution of phosphate by HEPES and storage of spinal cord explants for 2-4 d at $4^{\circ} \mathrm{C}$; see Materials and Methods) did not appear to interfere with muscle cell development or ncuritc outgrowth. Nor was the influence of the neurites on the muscle cells diminished. As summarized in Table 1, about $80 \%$ of the nerve-contacted muscle cells had AChRs and ChE localized along the path of contact and this percentage was somewhat higher than in previous studies. Over the rest of their surface, the nerve-contacted muscle cells had a reduced incidence of nonsynaptic $\mathrm{AChR}$ and $\mathrm{ChE}$ patches, compared to noncontacted muscle cells. This remote influence of nerve contact was also moderately greater than in previous studies. The enhanced neural influence may be attributable to the specific modifications of the culture method adopted in the present study or to other uncontrolled variables. One other minor difference between the control cultures in this study and in previous studies was that the incidence of $\mathrm{AChR}$ patches on the noncontacted muscle cells 


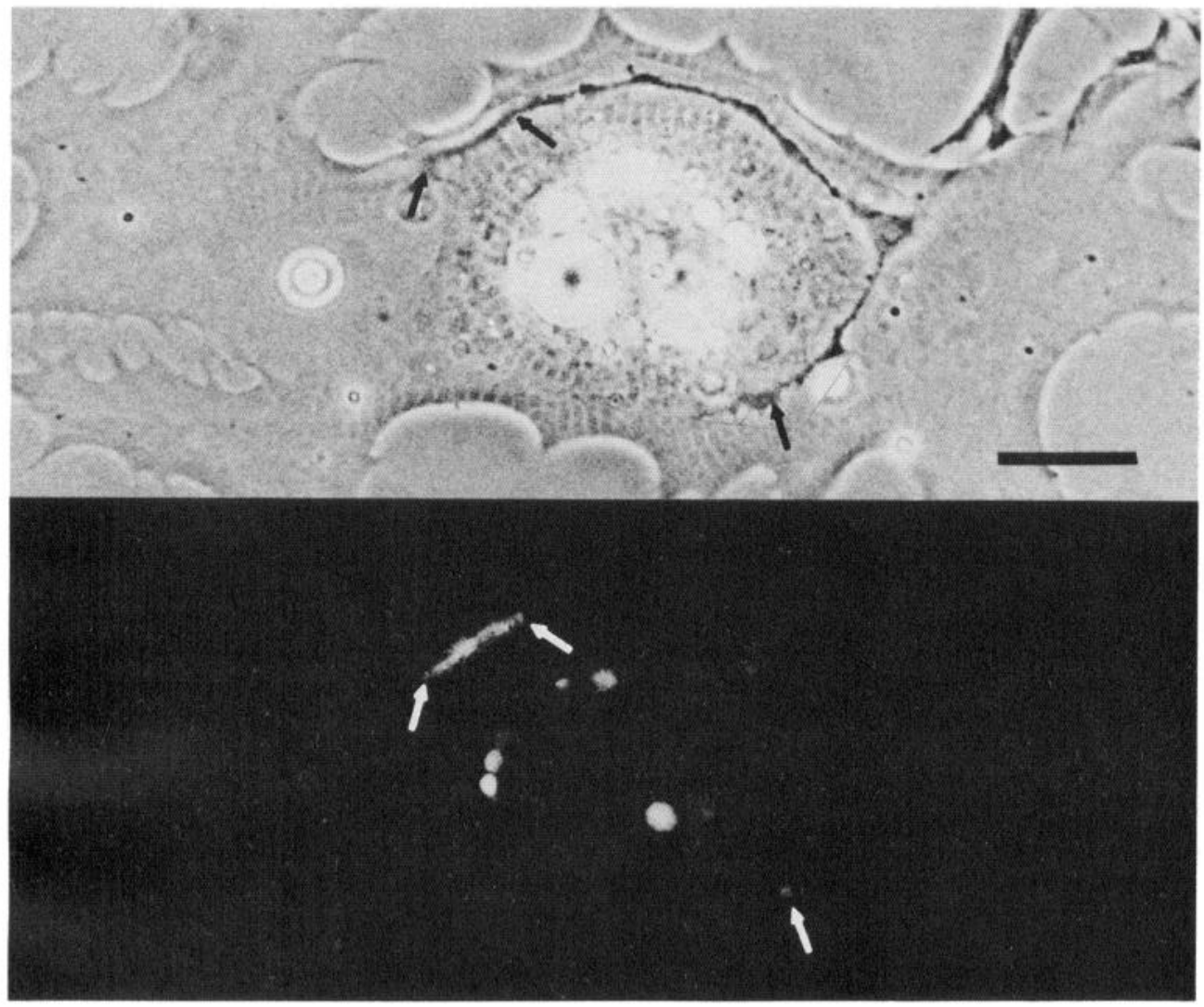

Figure 1. Phase (upper) and rhodamine fluorescence (lower) micrographs of the same nerve-contacted muscle cell grown in a medium containing both TTX and manganese to abolish action potentials. AChR staining is localized along parts of the nerve contact (arrows). The fluorescent profiles not corresponding to the nerve contact are associated with intracellular organelles and do not represent AChR staining. Scale bar, $20 \mu \mathrm{m}$.

was slightly reduced, both on the lower and upper surfaces of the cells.

\section{Effect of tetrodotoxin (TTX)}

Tetrodotoxin (TTX), at a concentration $(1.2 \mu \mathrm{mol} / \mathrm{liter})$ that blocks sodium action potentials in Xenopus neurons (e.g., Cohen, 1972; Kullberg et al., 1977; Willard, 1980), did not affect the plating and growth of the nerve. Examination of the cultures for $\mathrm{AChR}$ and $\mathrm{ChE}$ distribution showed that the nerve, even though blocked by TTX, was still able to influence the localization of these molecules (Table 1). AChR and ChE accumulated at a high proportion of nerve-muscle contacts, and the nerve-contacted muscle cells had a reduced incidence of AChR and $\mathrm{ChE}$ patches away from the sites of contact. In comparing the TTX results with the corresponding control results in Table 1 , the only statistically significant difference is the slightly greater incidence of ChE localization at nerve-muscle contacts $(p<$ 0.05 ; Mann-Whitney $U$ test) in TTX cultures $(85 \%)$ than in control cultures (79\%). There was a tendency for the contacts in TTX cultures to appear more brightly stained by the rhodamine $\alpha$-bungarotoxin than contacts in control cultures. An impression was also gained that some of these contacts had AChR localized among a greater portion of the contact, but no attempt was made to quantify these impressions.

\section{Effect of reduced external calcium and calcium antagonists}

When Xenopus spinal cord neurons first become excitable, in vivo or in culture, their action potentials are not blocked by TTX, but are blocked by calcium antagonists such as cobalt and manganese (Spitzer, 1979, 1983). As development proceeds, this calcium action potential is replaced by a sodium action potential which is sensitive to TTX. The conversion from calcium to sodium action potentials occurs in a few days for neuronal cell bodies and in a few hours for neurites (Baccaglini and Spitzer, 1977; Willard, 1980). These findings raise the possibility that the neural influence that persisted in the presence of TTX might be dependent upon initial calcium action potentials. To investigate this possibility, the culture medium was modified with the aim of preventing the generation of both types of action potential.

For one set of experiments, the modified culture medium contained $1.2 \mu \mathrm{M}$ TTX and $10 \mathrm{~mm} \mathrm{MgCl}_{2}$ but no calcium salts. No attempt was made to chelate residual calcium or calcium leaking from the cells. In this regard it is interesting to note that chelation of external calcium severely inhibits clustering of AChRs, even on muscle cells not contacted by nerve (Henderson et al., 1984; Peng, 1984). Such conditions, which inhibit the muscle cells' ability to cluster AChRs, would militate against evaluating the role of neural impulses in nerve-induced changes in AChR distribution. Moreover, simple replacement of $\mathrm{CaCl}_{2}$ by $10 \mathrm{mM} \mathrm{MgCl}_{2}$ is sufficient to block calcium action potentials in cultured Xenopus neurons (Bixby and Spitzer, 1984a). Therefore, culture medium containing TTX and $10 \mathrm{~mm} \mathrm{MgCl}$ but no calcium salts would be expected to prevent entirely the generation of nerve impulses.

The nerve adhered to the substratum and neurite growth appeared normal in this modified culture medium. The effect of nerve contact on muscle cells at the site of contact was essentially indistinguishable from that in control media, both in $\mathrm{AChR}$ and ChE localization (Table 1). The incidence of $\mathrm{AChR}$ patches elsewhere on the nerve-contacted muscle cells was somewhat higher than in control cultures, particularly on the lower surface of the cells, but was still greatly reduced compared to noncontacted muscle cells. The incidence of nonsynaptic $\mathrm{ChE}$ patches was even less than in control cultures (Table 1). Taken together, the results indicate that a strong neural influence persisted even when $\mathrm{Ca}^{2+}$ ions were omitted from the TTX-culture medium and replaced by $10 \mathrm{~mm} \mathrm{MgCl}_{2}$.

In an additional set of experiments, calcium antagonists were tested, but only manganese proved useful. Cobalt ( $2 \mathrm{mmol} / \mathrm{liter})$ 
Figure 2. Two nerve-contacted muscle cells from a TTX-manganese culture following fixation and histochemical localization of ChE. The reaction product is associated with regions of nerve contact (arrows). Scale bar, $20 \mu \mathrm{m}$.

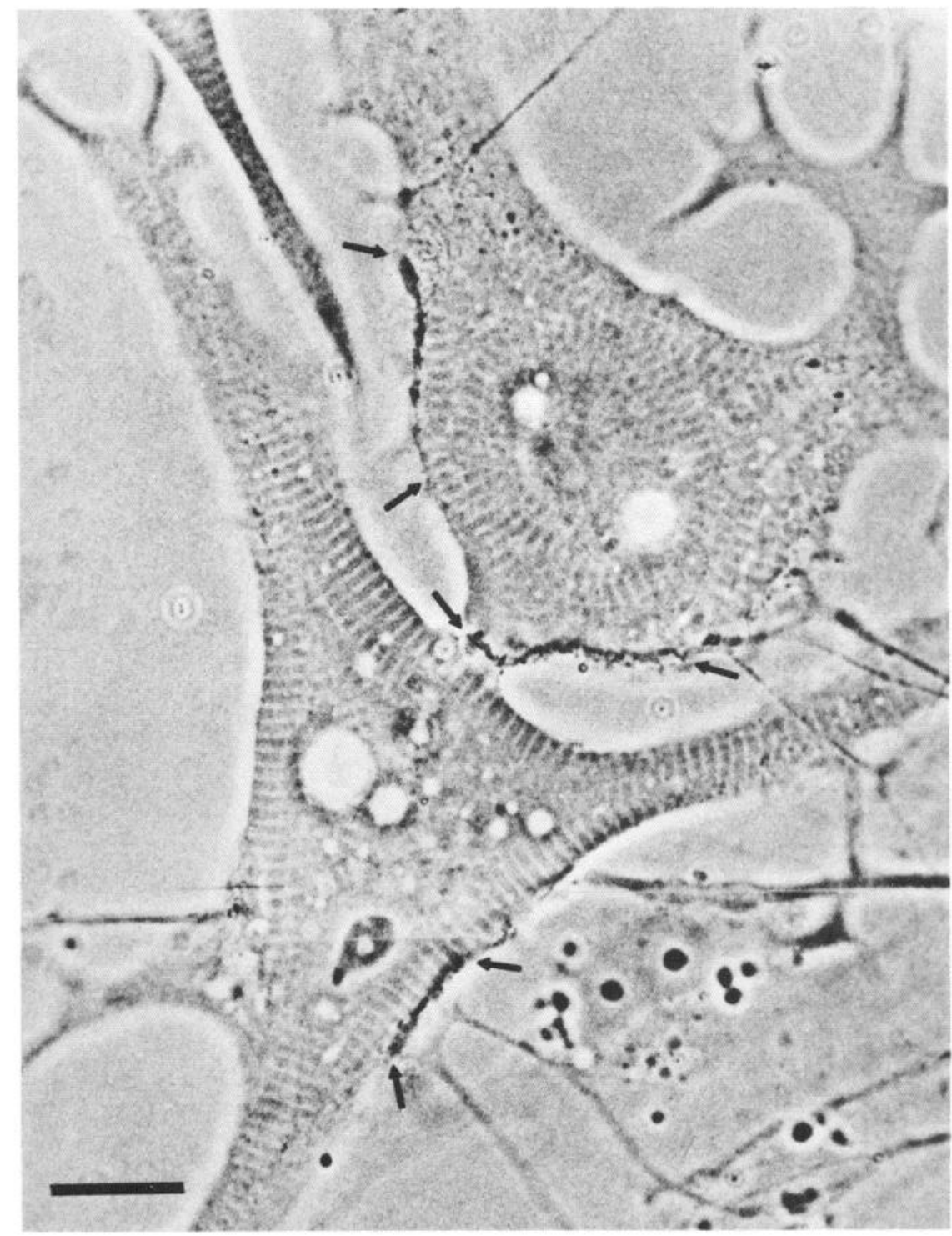

decreased the survival of the muscle cells and severely limited neurite expression, so that nerve-muscle contacts were not observed. Cadmium ( $1 \mathrm{mmol} / \mathrm{liter})$ and D-600 $(\approx 0.5 \mathrm{mg} / \mathrm{ml})$ were even more toxic. Manganese also reduced the survival of the muscle cells but did not appreciably inhibit neurite growth. Accordingly, the neural influence was examined in the combined presence of TTX (1.2 $\mu \mathrm{mol} / \mathrm{liter})$ and manganese at a concentration ( $2 \mathrm{mmol} / \mathrm{liter}$ ) that is known to abolish calcium action potentials in Xenopus neurons (Baccaglini and Spitzer, 1977; Spitzer, 1979) and spontaneously occurring endplate potentials in unanesthetized Xenopus embryos (Blackshaw and Warner, 1976).

Both AChR and ChE staining were less intense in the MnTTX cultures, and this was the case even on noncontacted muscle cells. AChR and ChE patches on noncontacted muscle cells also appeared smaller. The reduction in brightness and size seemed to be progressive and was presumably related to the declining survival of the muscle cells caused by manganese. Despite the toxic effects of manganese, a large fraction of the nerve-contacted muscle cells did exhibit AChR (Fig. 1) and ChE (Fig. 2) localization along the path of contact (Table 1), but the portion of contact occupied by ACh stain did not appear to be as great as in cultures grown without manganese. In addition, when compared to noncontacted muscle cells, the nerve-con- tacted ones exhibited a marked reduction in the incidence of nonsynaptic AChR and ChE patches (Table 1). These results indicate that the local and remote influences of nerve contact persisted even under conditions that block both sodium and calcium action potentials.

\section{Effect of high external potassium}

Chronic recordings have not been made from competent neurons in control cultures, and consequently it remains unknown how much impulse activity actually occurs in the absence of impulse blockers. If, in fact, there is little impulse activity in control cultures, then impulse blockers would not be expected to have any marked effect on the nerve-induced changes in $\mathrm{AChR}$ and ChE distribution. Conversely, an increase in impulse activity might reveal an enhanced neural influence. Since some effects of nerve impulses, such as the release of synaptic transmitter, can be mimicked by $\mathrm{K}^{+}$-induced depolarization, we examined the effects of a high $\mathrm{K}^{+}$culture medium (see Materials and Methods) on $\mathrm{AChR}$ and $\mathrm{ChE}$ distribution. By depolarizing the cultured cells, the high $\mathrm{K}^{+}$medium would also be expected to prevent the generation of action potentials.

In order to minimize potassium-induced contraction, and the associated detachment of muscle cells from the substratum, two protocols were adopted (see Materials and Methods). Both 
Table 2. The effect of high potassium ion concentration on the localization of $\mathrm{AChRs}$ and $\mathrm{ChE}$

\begin{tabular}{|c|c|c|c|c|c|}
\hline \multirow[b]{2}{*}{ Culture medium } & \multirow{2}{*}{$\begin{array}{l}\text { Stain } \\
\text { at contact } \\
\text { (\% nerve- } \\
\text { contacted } \\
\text { cells) }\end{array}$} & \multicolumn{2}{|c|}{$\begin{array}{l}\text { Nonsynaptic stain on } \\
\text { lower surface (\% cells) }\end{array}$} & \multicolumn{2}{|c|}{$\begin{array}{l}\text { Nonsynaptic stain on } \\
\text { upper surface ( } \% \text { cells) }\end{array}$} \\
\hline & & $\begin{array}{l}\text { Nerve- } \\
\text { contacted } \\
\text { cells }\end{array}$ & $\begin{array}{l}\text { Cells not } \\
\text { contacted } \\
\text { by nerve }\end{array}$ & $\begin{array}{l}\text { Nerve- } \\
\text { contacted } \\
\text { cells }\end{array}$ & $\begin{array}{l}\text { Cells not } \\
\text { contacted } \\
\text { by nerve }\end{array}$ \\
\hline \multicolumn{6}{|l|}{ AChR stain } \\
\hline Control & 85 & $3(80)$ & $76(90)$ & 9 & 70 \\
\hline High K Method 1 & 89 & $4(83)$ & $68(150)$ & 4 & 67 \\
\hline High K Method 2 & 87 & $1(105)$ & $6(123)$ & 0 & 2 \\
\hline \multicolumn{6}{|l|}{ ChE stain } \\
\hline Control & 79 & $49(80)$ & $100(90)$ & 25 & 63 \\
\hline High K Method 1 & 83 & $52(75)$ & $93(151)$ & 38 & 72 \\
\hline High K Method 2 & 100 & $13(8)$ & $60(105)$ & 25 & 4 \\
\hline
\end{tabular}

Cultures were exposed to a high $\mathrm{K}^{+}$ion medium using onc of two mcthods. In the first, muscle was grown for $2-4 \mathrm{~d}$, then slowly transferred to the high $\mathrm{K}^{+}$medium. Nerve was then plated and cultures were grown for a further $1-2 \mathrm{~d}$. In the second, nerve and muscle were plated together into the high $\mathrm{K}^{+}$ion medium. In most cases the number of counts obtained from one culture was small; the results from seven Method 1 and five Method 2 cultures have been pooled. The number of cells counted is in parentheses. Only eight nerve-contacted muscle cells could be reliably identified for $\mathrm{ChE}$ distribution in Method 2 cultures because many of the nerve explants were dislodged during fixation of these cultures.

methods appeared to reduce neurite outgrowth, so that relatively few nerve-muscle contacts were seen in the high $\mathrm{K}^{+}$cultures. Further, both methods markedly reduced the survival of the muscle cells and neurites, so that few contacts survived until the time the $\mathrm{ChE}$ histochemistry was performed. In addition, many nerve explants were lost when the cultures were fixed. As a consequence, in some of the cultures few contacts could be examined for ChE localization.

Despite the apparent retardation of nerve growth, the neural influence on $\mathrm{AChR}$ and $\mathrm{ChE}$ localization was pronounced (Table 2). Because of the small number of contacts per culture, the results from all cultures have been pooled for each experimental group. High $\mathrm{K}^{+}$cultures made by Method 1 gave essentially the same results as control cultures with respect to the localization of AChR (Fig. 3) and ChE at nerve-muscle contacts, and the reduction of non-synaptic $A C h R$ and $\mathrm{ChE}$ patches elsewhere on the nerve-contacted muscle cells. When muscle cells were grown from the start in high $\mathrm{K}^{+}$medium (Method 2), the occurrence of $\mathrm{AChR}$ and $\mathrm{ChE}$ patches on noncontacted musclc cclls was very much less than in control cultures, indicating that the high $\mathrm{K}^{+}$medium interfered with the formation of nonsynaptic patches independently of nerve contact. Yet even in these cultures, the fraction of nerve-contacted muscle cells that exhibited AChR and $\mathrm{ChE}$ localization along the path of contact was at least as high as in control cultures (Table 2). Furthermore, in some cases, AChRs and $\mathrm{ChE}$ were localized along the entire length of nervemuscle contact. Thus even though the muscle cells in the high $\mathrm{K}^{+}$medium exhibited a reduced survival and a great reduction in the formation of nonsynaptic patches, the local influence of the nerve under these conditions remained undiminished (Fig. 4). The very low incidence of patches on the noncontacted muscle cells of Method 2 cultures and the small number of nervecontacted cells observed following ChE histochemistry preclude any conclusions concerning the remote neural influence with this method. Nevertheless, it is clear from the results of Method 1 that the remote neural influence also persisted in the high $\mathrm{K}^{+}$ medium.

\section{Discussion}

Previous studies of cultures of spinal cord and myotomal muscle cells derived from Xenopus embryos have indicated that competent neurites trigger profound changes in the distribution of AChRs and ChE on the muscle cells they contact. They cause a local accumulation of AChRs and ChE at the site of contact, and they cause a decrease in the occurrence of AChR patches and ChE patches elsewhere on the contacted muscle cells by inhibiting their formation and by reducing the survival of any pre-existing nonsynaptic patches. By growing cultures in the presence of postsynaptic blocking agents, it has been found that each of these nerve-induced changes can occur in the absence of muscle impulses (Anderson and Cohen, 1977; Anderson et al., 1977; Moody-Corbett and Cohen, 1982; Moody-Corbett et al., 1982), a conclusion confirmed by the results of the present study. The accumulation of $\mathrm{AChRs}$ and $\mathrm{ChE}$ at the sites of nerve contact and the decreased occurrence of nonsynaptic AChR patches have also been documented in studies of chick and rat neuromuscular synaptogenesis. In the latter species, the accumulation of AChRs at nerve-muscle contacts can occur in the absence of muscle action potentials (Rubin et al., 1980; Steinbach, 1974), but the localization of ChE at nerve-muscle contacts and the decreased incidence of nonsynaptic $A C h R$ patches require muscle impulse activity (Harris, 1981; Lømo and Slater, 1980b; Rubin et al., 1980; Weinberg and Hall, 1979; ZiskindConhaim and Bennett, 1982). Since the local and remote effects of neurites can occur in the absence of muscle action potentials in cultures of Xenopus spinal cord and myotomal muscle, it has been possible in the present study to use impulse-blocking agents to evaluate whether nerve impulse activity is required for the nerve to trigger these effects.

The findings indicate that the influence of the nerve was essentially undiminished by TTX or by culture medium that contained TTX and $10 \mathrm{mmol} / \mathrm{liter} \mathrm{Mg}$, but no calcium. Besides preventing the generation of sodium action potentials, the $\mathrm{Mg}$ enriched, $\mathrm{Ca}$-deficient medium should have eliminated calcium action potentials in the neurons (Bixby and Spitzer, 1984b). Likewise, in culture medium containing TTX and Mn, the generation of both sodium and calcium action potentials should have been prevented entirely (Baccaglini and Spitzer, 1977; Spitzer, 1979). Yet these modified culture media failed to abolish the local and remote influences of the nerve on AChR and ChE localization. The TTX-Mn culture medium did appear to reduce the amount of $A C h R$ and $\mathrm{ChE}$ accumulation at individual nerve-muscle contacts. But it also appeared to reduce the size of nonsynaptic patches and the density of AChRs and ChE at these patches, even on noncontacted muscle cells, thereby suggesting that Mn had an inhibitory effect on the muscle mech- 

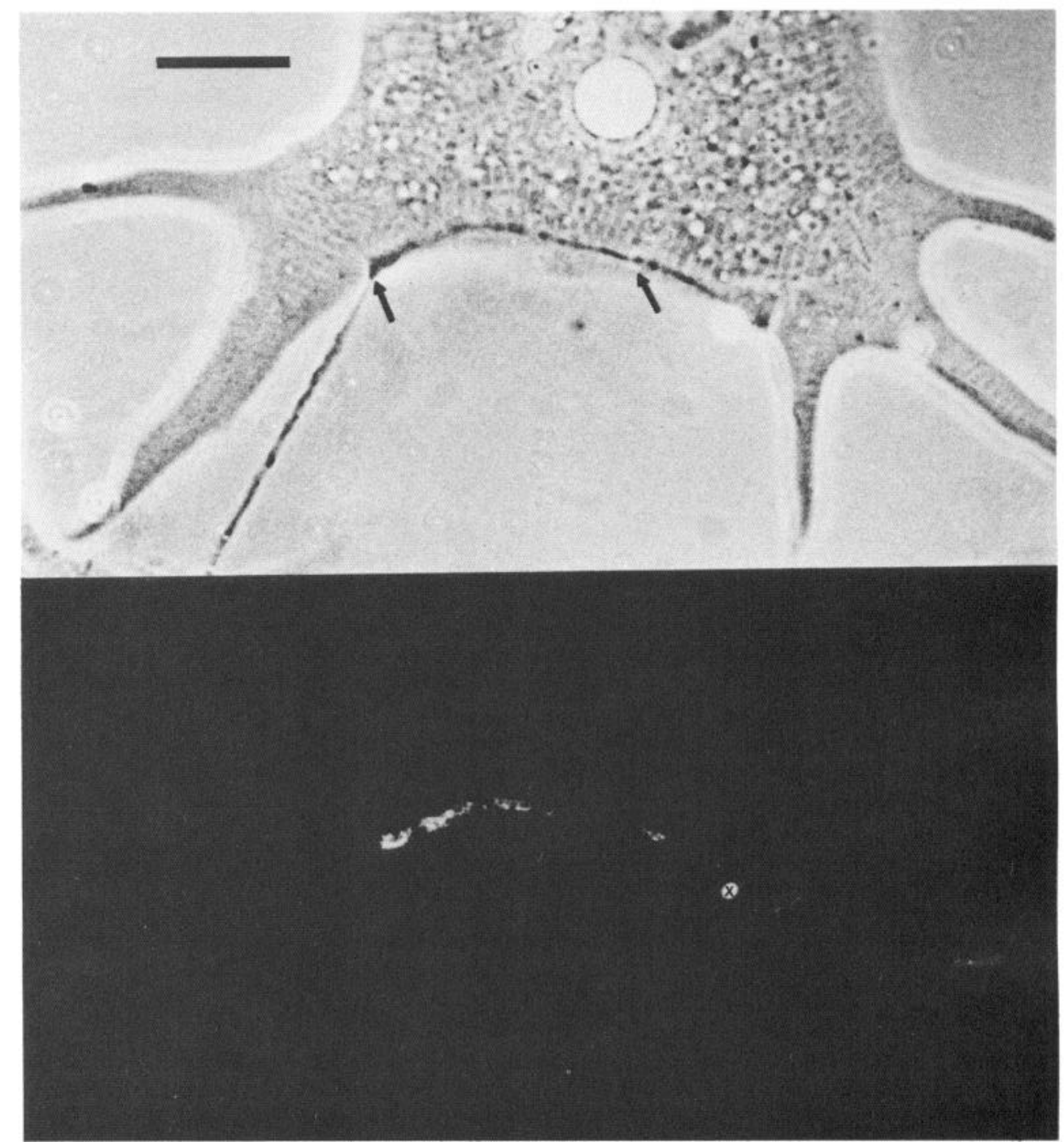

Figure 3. Nerve-contacted muscle cell grown in high $\mathrm{K}^{+}$medium (Method 1). Except for the artifactual spot $(x)$ on the fluorescence micrograph, note that all staining is associated with the nerve contact (arrows on phase micrograph). Scale bar, $20 \mu \mathrm{m}$.

anisms that participate in the localization of AChRs and ChE. This interpretation is in agreement with the finding that manganese moderately inhibits bead-induced formation of $\mathrm{AChR}$ patches (Peng, 1984). Considered together with the quantitative data in Table 1 , it would seem that the triggering action of the nerve may not have been diminished at all in the presence of TTX and Mn. In any event, it is apparent that the neural agent(s) that triggers the changes in AChR and ChE localization can be supplied to the neurites and externalized in the absence of sodium and calcium action potentials. Other features of neuronal differentiation, including changes in the ionic dependency of the action potential, development of sensitivity to $\gamma$-aminobutyric acid, and the establishment of synaptic function, can also occur in the absence of sodium and calcium action potentials (Bixby and Spitzer, 1984a; Henderson et al., 1984).

The occurrence of nerve-induced changes in AChR and ChE localization in high $\mathrm{K}^{+}$culture medium provides additional support for the conclusion that the neural influence can operate in the absence of nerve (and muscle) impulses. These findings also indicate that the underlying muscle mechanisms can be activated when the resting potential of the muscle cell is greatly diminished. Another implication of the high $\mathrm{K}^{+}$experiments follows from the finding that even though the high $\mathrm{K}^{+}$medium inhibited the formation of AChR and ChE patches on noncontacted muscle cells, the localization of AChRs and ChE at nerve- muscle contacts was not inhibited. Perhaps the response of the muscle cells to the neurite factor is enhanced by the depolarization. An alternative interpretation is that the $\mathrm{K}^{+}$-induced depolarization of the neurons enhanced the supply and/or externalization of the triggering agent, but that the full effect of the triggering agent was not observed because the high $\mathrm{K}^{+}$medium had an inhibitory effect on the muscle mechanisms that participate in the localization of AChRs and ChE. According to this interpretation, nerve impulse activity might also be expected to enhance the triggering action of the neurites. Such a suggestion is not contradicted by the finding that impulse blockers did not appreciably affect the nerve-induced changes in AChR and ChE localization. There may be little impulse activity in the competent neurons even in control cultures. The competent neurons functionally innervate the muscle cells they contact (Anderson et al., 1977, 1979; Kidokoro et al., 1980), and are therefore likely to be motor neurons. The culture medium contains a high concentration of glycine $(\approx 1.8 \mathrm{mmol} /$ liter $)$, which would be expected in control cultures to keep the motor neurons hyperpolarized (Bixby and Spitzer, 1984b) and thereby inhibit the generation of action potentials. In line with this suggestion is that culture medium abolishes motor behavior in skinned Xenopus embryos (unpublished observations).

The following view thus emerges. A factor (or factors), present on the surface of the neurites or released from the neurites, acts 


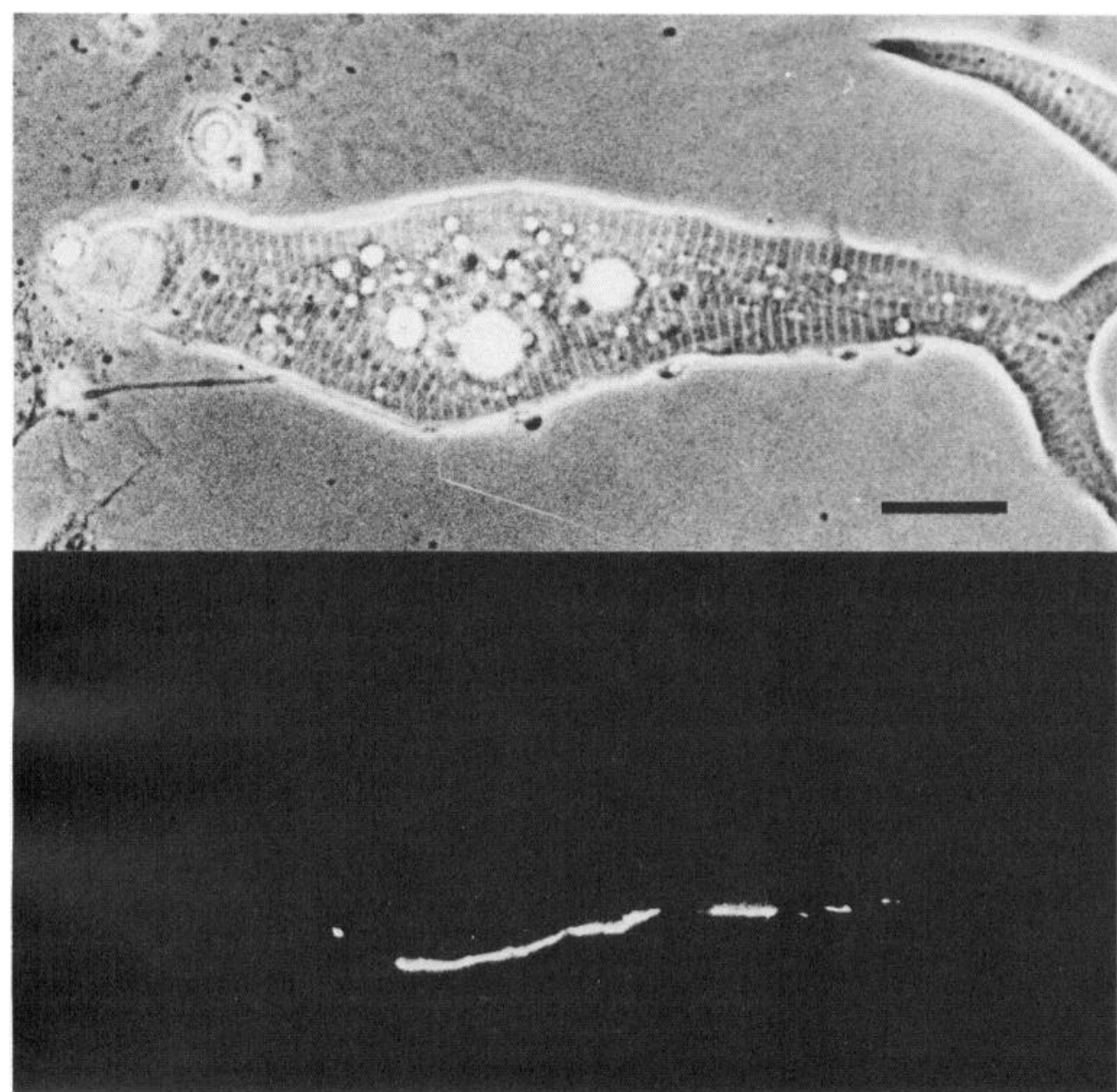

Figure 4. Nerve-contacted muscle cell grown in high $\mathrm{K}^{+}$medium (Method 2). Long lengths of $A C h R$ staining occurred at sites of nerve contact, despite the fact that uncontacted cells only rarely had receptor patches. Scale bar, $20 \mu \mathrm{m}$. on neurite-contacted muscle cells to trigger a set of muscle mechanisms which direct AChRs and ChE to accumulate at the site of contact rather than elsewhere on the muscle cell. The supply of this factor to the neurites and its externalization can occur in the absence of nerve impulses and is not prevented by a large reduction in resting potential. Likewise, the response of the muscle cells to the factor can occur in the absence of muscle impulses and when the muscle cells are largely depolarized.

\section{References}

Anderson, M. J., and M. W. Cohen (1977) Nerve-induced and spontaneous redistribution of acetylcholine receptors on cultured muscle cells. J. Physiol. (Lond.) 268: 757-773.

Anderson, M. J., M. W. Cohen, and E. Zorychta (1977) Effects of innervation on the distribution of acetylcholine receptors on cultured muscle cells. J. Physiol. (Lond.) 268: 731-756.

Anderson, M. J., Y. Kidokoro, and R. Gruener (1979) Correlation between acetylcholine receptor localization and spontaneous synaptic potentials in cultures of nerve and muscle. Brain Res. 166: 185-190.

Baccaglini, P. I., and N. C. Spitzer (1977) Developmental changes in the inward current of the action potential of Rohon-Beard neurones. J. Physiol. (Lond.) 271: 93-117.

Betz, H., J.-P. Bourgeois, and J.-P. Changeux (1980) Evolution of cholinergic proteins in developing slow and fast skeletal muscles in chick embryo. J. Physiol. (Lond.) 302: 197-218.

Bevan, S., and J. H. Steinbach (1977) The distribution of $\alpha$-bungarotoxin binding sites on mammalian skeletal muscle developing in vivo. J. Physiol. (Lond.) 267: 195-213.

Bixby, J. L., and N. C. Spitzer (1984a) Early differentiation of vertebrate spinal neurons in the absence of voltage dependent $\mathrm{Ca}^{2+}$ and $\mathrm{Na}^{+}$influx. Dev. Biol. 106: 89-96.
Bixby, J. L., and N. C. Spitzer (1984b) The appearance and development of neurotransmitter sensitivity in Xenopus embryonic spinal neurones in in vitro. J. Physiol. (Lond.) 353: 143-155.

Blackshaw, S., and A. Warner (1976) Onset of acetylcholine sensitivity and end-plate activity in developing myotome muscles of Xenopus. Nature 262: 217-218.

Braithwaite, A. W., and A. J. Harris (1979) Neural influence on acetylcholine receptor clusters in embryonic development of skeletal muscle. Nature 279: 549-551.

Cangiano, A., T. Lomo, L. Lutzemberger, and O. Sveen (1980) Effects of chronic nerve conduction block on formation of neuromuscular junctions and junctional $\mathrm{AChE}$ in the rat. Acta Physiol. Scand. 109: 283-296.

Chow, I., and M. W. Cohen (1983) Developmental changes in the distribution of acetylcholine receptors in the myotomes of Xenopus laevis. J. Physiol. (Lond.) 339: 533-571.

Cohen, M. W. (1972) The development of neuromuscular connexions in the presence of D-tubocurarine. Brain Res. 41: 457-463.

Cohen, M. W., and P. R. Weldon (1980) Localization of acetylcholine receptors and synaptic ultrastructure at nerve-muscle contacts in culture: Dependence on nerve type. J. Cell Biol. 86: 388-401.

Cohen, M. W., M. Greschner, and M. Tucci (1984) In vivo development of cholinesterase at a neuromuscular junction in the absence of motor activity in Xenopus laevis. J. Physiol. (Lond.) 348: 57-66.

Cohen, M. W., F. Moody-Corbett, P. R. Weldon, and D. F. Davey (1983) Neural regulation of acetylcholine receptors and cholinesterase on the surface of embryonic muscle cells. Proc. Int. Union Physiol. Sci. 15: 383.

Davey, D. F., and M. W. Cohen (1982a) Impulse independent localization of acetylcholine receptors and cholinesterase at sites of nerve contact on embryonic Xenopus muscle cells in culture. Neurosci. Lett. 8 (Suppl): S41.

Davey, D. F., and M. W. Cohen (1982b) Localization of acetylcholine 
receptors and cholinesterase at sites of nerve contact on embryonic Xenopus muscle cells cultured in high potassium medium. Proc. Aust. Physiol. Pharmacol. Soc. 13: 43P.

Frank, E., and G. D. Fischbach (1979) Early cvents in ncuromuscular junction formation in vitro. Induction of acetylcholine receptor clusters in the postsynaptic membrane and morphology of newly formed synapses. J. Cell Biol. 83: 143-158.

Gordon, T., R. Perry, A. R. Tuffery, and G. Vrbová (1974) Possible mechanisms determining synapse formation in developing skeletal muscles of the chick. Cell Tissue Res. 155: 13-25.

Harris, A. J. (1981) Embryonic growth and innervation of rat skeletal muscles. III. Neural regulation of junctional and extrajunctional acetylcholine receptor clusters. Philos. Trans. R. Soc. Lond. [Biol.] 293: 287-314.

Henderson, L. P., M. A. Smith, and N. C. Spitzer (1984) The absence of calcium blocks impulse-evoked release of acetylcholine but not $d e$ novo formation of functional neuromuscular synaptic contacts in culturc. J. Ncurosci. 4: 3140-3150.

Jacob, M., and T. L. Lentz (1979) Localization of acetylcholine receptor by means of horseradish peroxidase- $\alpha$-bungarotoxin during formation and development of the neuromuscular junction in the chick embryo, J. Cell Biol. 82: 195-211.

Karnovsky, M. J. (1964) The localization of cholinesterase activity in rat cardiac muscle by electron microscopy, J. Cell Biol. 23: 217-232.

Kidokoro, Y., M. J. Anderson, and R. Gruener (1980) Changes in synaptic potential properties during acetylcholine receptor accumulation and neuro-specific interactions in Xenopus nerve-muscle cell culture. Dev. Biol. 78: 464-483.

Kullberg, R. W., T. L. Lentz, and M. W. Cohen (1977) Development of the myotomal neuromuscular junction in Xenopus laevis: An electrophysiological and fine-structural study. Dev. Biol. 60: 101-129.

Kuromi, H., and Y. Kidokoro (1984) Nerve disperses preexisting acetylcholine receptor clusters prior to induction of receptor accumulation in Xenopus muscle cultures. Dev. Biol. 103: 53-61.

Lømo, T., and C. R. Slater (1980a) Acetylcholine sensitivity of developing ectopic nerve-muscle junctions in adult rat soleus muscles. J. Physiol. (Lond.) 303: 173-189.

Lomo, T., and C. R. Slater (1980b) Control of junctional acetylcholinesterase by neural and muscular influences in the rat, J. Physiol. (Lond.) 303: 191-202.

Moody-Corbett, F., and M. W. Cohen (1981) Localization of cholinesterase at sites of high acetylcholine receptor density on embryonic amphibian muscle cells cultured without nerve. J. Neurosci. $1: 596-$ 605.

Moody-Corbett, F., and M. W. Cohen (1982) Influence of nerve on the formation and survival of acetylcholine receptor and cholinesterase patches on embryonic Xenopus muscle cells in culture. J. Neurosci. 2: 633-646.

Moody-Corbett, F., P. R. Weldon, D. F. Davey, and M. W. Cohen (1981) Cholinesterase localization at sites of nerve contact on embryonic Xenopus muscle cells in culture. Soc. Neurosci. Abstr. 7:670.

Moody-Corbett, F., P. R. Weldon, and M. W. Cohen (1982) Cholinesterase localization at sites of nerve contact on embryonic amphibian muscle cells in culture. J. Neurocytol. 11: 381-394.

Nieuwkoop, P. D., and J. Faber (1967) Normal Table of Xenopus laevis (Daudin), 2nd Ed., North-Holland, Amsterdam.

Peng, H. B. (1984) Participation of calcium and calmodulin in the formation of acetylcholine receptor clusters. J. Cell Biol. 98: 550557.

Rubin, L. L., S. M. Schuetze, C. L. Wcill, and G. D. Fischbach (1980) Regulation of acetylcholinesterase appearance at neuromuscular junctions in vitro. Nature 283: 264-267.

Sohal, G. S., and R. W. Wrenn (1984) Appearance of high-molecularweight acetylcholinesterase in aneural muscle developing in vivo. Dev. Biol. 101: 229-234.

Spitzer, N. C. (1979) Ion channels in development. Annu. Rev. Neurosci. 2: 363-397.

Spitzer, N. C. (1983) The development of neuronal membrane properties in vivo and in culture. In Developing and Regenerating Vertebrate Nervous Systems, P. W. Coates, R. R. Markwald, and A. D. Kenny, eds., pp. 41-59, Alan R. Liss, New York.

Spitzer, N. C., and J. L. Bixby (1982) Appearance and develoment of chemosensitivity of embryonic amphibian spinal neurons in vitro. Soc. Ncurosci. Abstr. 8: 130.

Steinbach, J. H. (1974) Role of muscle activity in nerve-muscle interaction in vitro. Nature 248: 70-71.

Weinberg, C. B., and Z. W. Hall (1979) Junctional form of acetylcholinesterase restored at nerve-free end plates. Dev. Biol. 68: 631-635.

Willard, A. L. (1980) Electrical excitability of outgrowing neurites of embryonic neurones in cultures of dissociated neural plate of Xenopus laevis. J. Physiol. (Lond.) 301: 115-128.

Ziskind-Conhaim, L., and J. I. Bennett (1982) The effects of electrical inactivity and denervation on the distribution of acetylcholine receptors in developing rat muscle. Dev. Biol. 90: 185-197. 